\title{
Effect of alloy elements on the anti-corrosion properties of low alloy steel
}

\author{
BAORONG HOU*, YANTAO LI, YANXU LI and JINGLEI ZHANG \\ Institute of Oceanology, Chinese Academy of Sciences, Qingdao 266071
}

MS received 27 December 1999

\begin{abstract}
Effect of alloy elements on corrosion of low alloy steel was studied under simulated offshore conditions. The results showed that the elements $\mathrm{Cu}, \mathrm{P}, \mathrm{Mo}, \mathrm{W}, \mathrm{V}$ had evident effect on corrosion resistance in the atmosphere zone; $\mathrm{Cu}, \mathrm{P}, \mathrm{V}$, Mo in the splash zone and $\mathrm{Cr}$, Al, Mo in the submerged zone.
\end{abstract}

Keywords. Low alloy steel; anti-corrosion; electric connection.

\section{Introduction}

The anti-corrosion properties of steel in marine environment had long been studied, although there are only a few reported studies on the relationship between the anticorrosion properties of steel and alloy elements. $\mathrm{Ni}-\mathrm{Cu}-\mathrm{P}$ anti-sea corrosion steel was first invented in 1951 in America. The result showed that the relationship between anti-corrosion properties of steel in marine environment and alloy elements was considerably different with variation of marine environment (Hou and Zhang 1980). The same alloy element's effect on the anti-corrosion properties of steel in the splash and immersion zones was also evidently different. The effects of alloy element on marine structures (such as oil-platform, steel-pile wharf, etc) in the sea mud zone, submerged zone, tidal zone, splash zone, and marine atmospheric zone were entirely different (Hou 1981). It was reported that a certain kind of alloy element can improve the corrosion resistance of steel in the splash zone, but not in the seawater zone, or even accelerate the corrosion rate there (Xia et al 1995).

To study the relationship between alloy elements and corrosion resistance of steel, 50 types of steels containing various elements were hung in the marine atmospheric zone, splash zone, tidal zone and seawater zone for 90 days to 2 years by the electric connection method. In this paper, only the effects of 18 alloy elements on the corrosion resistance of steel under the same conditions are discussed.

\section{Materials and methods}

\subsection{Test equipment}

The effect of alloy elements on steel corrosion in marine environment by using an experimental device and the

*Author for correspondence method of simulated corrosion of electrically connected specimen plates in the open sea is shown in figure 1 (The same fixing methods were applied to the 18 kinds of steels). The number 5 sample in figure 1 was the experimental sample. There were totally 10 samples in the marine atmospheric zone, splash zone, tidal zone and seawater zone. The specimens were connected with lead wires in order to simulate well the long-scale hanging plate.

\subsection{Specimens}

2.2a The sizes of specimens and their treatments: Before the test the $50 \mathrm{~mm} \times 100 \mathrm{~mm} \times 6.0 \mathrm{~mm}$ specimens were polished with No. 400 sandpaper, washed, degreased with alcohol, dried and weighed. After the test, the specimens were immersed in $20 \% \mathrm{HCl}$ aqueous solution with $2 \%(\mathrm{CH})_{2} \mathrm{~N}_{4}$ inhibitor to remove corrosion products, then washed, neutralized, and weighed to calculate corrosion rate.

2.2b Specimens installation: The specimens were installed vertically facing southward in plastic frames, as shown in figure 1 , and were connected to each other with lead wires in order to simulate well the practical corrosion conditions in the open sea. The welding point was covered with epoxy resin to prevent corrosion due to contact with seawater.

\subsection{Test period}

Experiments on more than 50 kinds of low alloy steels were conducted by using a device for simulating the overmany-years-corrosion of electrically connected species in the open sea. The corrosion rates of different steels in 5 sections were tested, respectively. The test times were 
90 d, 180 d, 350 d, 2 y and 10 y, respectively. Results for 18 types of steels and 350 days of test time were selected to be analyzed in this paper. The chemical compositions of 18 types of steels are shown in figure 1 .

\section{Results and discussion}

The respective corrosion rates of 18 types of steels in marine atmospheric zone, splash zone and seawater zone are given in figures $2-4$. The corrosion rates of specimen 10 in the marine atmospheric zone are shown in figure 1. The corrosion rates of specimen 9 in figure 1 in the splash zone are shown in figure 3 . The corrosion rates of the same steel in the seawater zone as shown in figure 4 are the average corrosion rates of specimens $1-5$ in figure 1.

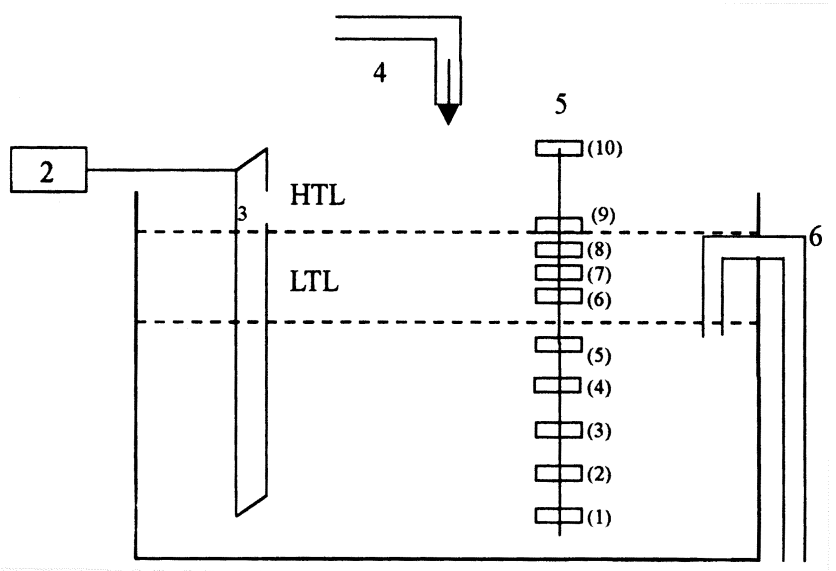

Figure 1. Experiment apparatus. (1. Test tank; 2. motor; 3. wave generator; 4 . seawater; 5 . electrically connected sample; 6. syphon tube (HTL: high tide level; LTL: low tide level)).
Figures 2-4 show that distinctly different carbon steel corrosion rates are mainly due to the different kinds and amounts of alloy elements added to carbon steel; and that the corrosion rates of the same steel in the marine atmospheric zone, splash zone and seawater zone also differed. For example, in the marine atmospheric zone (figure 2), the corrosion rates of $10 \mathrm{CuPV}$ steel and 1\# steel were the lowest, about $0.05 \mathrm{~mm} / \mathrm{a}$; the corrosion rate of $\mathrm{A}_{3}$ steel was the highest, about $0.25 \mathrm{~mm} / \mathrm{a}, 5$ times higher than the former. The corrosion rates differences were mainly due to the different kinds and amounts of alloy elements added to carbon steel.

In the splash zone (figure 3 ), the corrosion rate of $10 \mathrm{CuPV}$ steel was the lowest, $0.28 \mathrm{~mm} / \mathrm{a}$; the corrosion rate of $10 \mathrm{Cr}_{2} \mathrm{AlMo}$ steel was the highest, $0.54 \mathrm{~mm} / \mathrm{a}, 2$ times higher than the former. The corrosion rates of $10 \mathrm{Cr}_{2} \mathrm{AlMoRe}$ steel, 10CrAlMo steel, Sm4lC steel, $\mathrm{A}_{3}$ steel, 07SiAlV steel and 10PV steel were not much different.

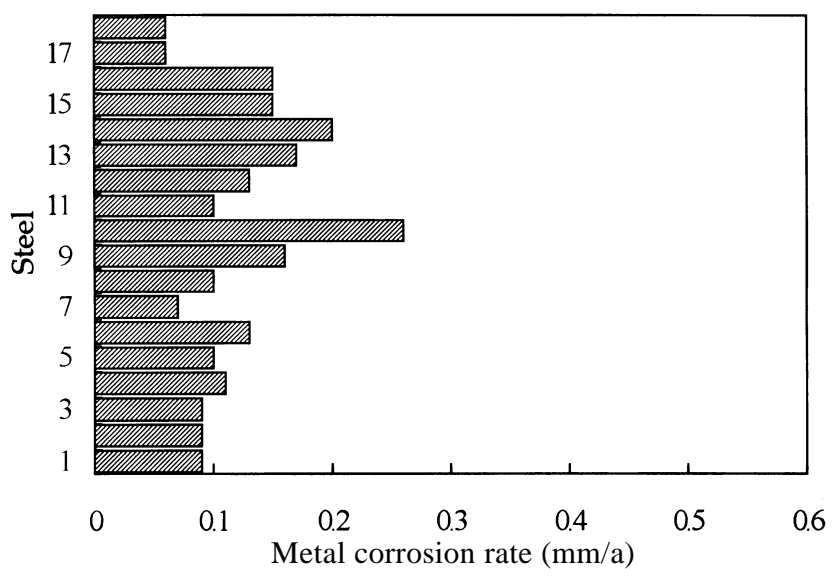

Figure 2. Corrosion rate of 18 types of steels in atmosphere.

Table 1. Chemical contents of test steels.

\begin{tabular}{|c|c|c|c|c|c|c|c|c|c|}
\hline No. & Steel & $\mathrm{Mn}$ & $\mathrm{P}$ & $\mathrm{Si}$ & $\mathrm{Cr}$ & Mo & $\mathrm{Al}$ & $\mathrm{Cu}$ & V \\
\hline 1 & 10MoWVRC & $0 \cdot 46$ & $0 \cdot 08$ & 0.03 & & 0.48 & & & $0 \cdot 104$ \\
\hline 2 & 10MoWPC & 0.47 & $0 \cdot 102$ & $0 \cdot 125$ & & $0 \cdot 46$ & & & $0 \cdot 122$ \\
\hline 3 & $16 \mathrm{MnCu} 1.45$ & 0.021 & $0 \cdot 4$ & & & & $0 \cdot 348$ & & \\
\hline 4 & $17 \mathrm{NiCuP}$ & $0 \cdot 61$ & $0 \cdot 124$ & $0 \cdot 058$ & & & & $0 \cdot 34$ & \\
\hline 5 & 15SiMoAl & 1.44 & $0 \cdot 018$ & $0 \cdot 57$ & & & $0 \cdot 2$ & & \\
\hline 6 & $10 \mathrm{CrAl}$ & $0 \cdot 51$ & 0.014 & 0.068 & $0 \cdot 41$ & & $0 \cdot 27$ & $0 \cdot 33$ & \\
\hline 7 & $10 \mathrm{Cr}_{2} \mathrm{AlMoRe}$ & $0 \cdot 62$ & $0 \cdot 011$ & $0 \cdot 27$ & 1.93 & $0 \cdot 33$ & $0 \cdot 89$ & $0 \cdot 12$ & \\
\hline 8 & $10 \mathrm{Cr}_{2} \mathrm{AlMo}$ & $0 \cdot 65$ & $0 \cdot 017$ & $0 \cdot 039$ & $2 \cdot 12$ & $0 \cdot 42$ & $0 \cdot 86$ & $0 \cdot 12$ & \\
\hline 9 & SM41C & $0 \cdot 68$ & $0 \cdot 017$ & $0 \cdot 25$ & & & & & \\
\hline 10 & $\mathrm{~A}_{3}$ & $0 \cdot 46$ & 0.006 & $0 \cdot 2$ & & & & & \\
\hline 11 & $10 \mathrm{NiCuCrAlNb}$ & 1.09 & $0 \cdot 047$ & $0 \cdot 45$ & 0.62 & & $0 \cdot 27$ & $0 \cdot 35$ & \\
\hline 12 & 07SiAlV & $0 \cdot 56$ & $0 \cdot 017$ & $0 \cdot 435$ & & & $0 \cdot 78$ & & $0 \cdot 15$ \\
\hline 13 & $10 \mathrm{CrNbCu}$ & $0 \cdot 4$ & $0 \cdot 116$ & $0 \cdot 047$ & $0 \cdot 29$ & & & $0 \cdot 1$ & \\
\hline 14 & 10PV & $0 \cdot 67$ & $0 \cdot 09$ & $0 \cdot 43$ & & & & & $0 \cdot 8$ \\
\hline 15 & $12 \mathrm{CuPV}$ & $0 \cdot 51$ & $0 \cdot 092$ & $0 \cdot 27$ & & & & 0.325 & 0.083 \\
\hline 16 & $12 \mathrm{MoPV}$ & $0 \cdot 54$ & $0 \cdot 091$ & $0 \cdot 27$ & & 0.52 & & & 0.08 \\
\hline 17 & $10 \mathrm{CuPV}$ & $0 \cdot 96$ & $0 \cdot 035$ & $0 \cdot 36$ & & & $0 \cdot 128$ & $0 \cdot 34$ & 0.055 \\
\hline 18 & Steel No. 1 & $0 \cdot 45$ & $0 \cdot 1$ & $0 \cdot 1$ & $0 \cdot 1$ & & & $0 \cdot 5$ & \\
\hline
\end{tabular}


In the seawater zone (figure 4), the corrosion resistance of $10 \mathrm{Cr}_{2} \mathrm{AlMoRe}$ steel was the highest; its corrosion rate was $0.08 \mathrm{~mm} / \mathrm{a}$; the corrosion rate of $\mathrm{A}_{3}$ steel was the highest, $0.265 \mathrm{~mm} / \mathrm{a}, 3$ times higher than the former.

Comparison of figures 2-4 shows that the corrosion rates of the same type of alloy steel in marine atmospheric zone, splash zone and seawater zone were different. The main corrosion rate of steels in the marine atmospheric zone was the lowest, that in the seawater zone was the second lowest. The corrosion rate of steel in the splash zone was the highest, usually 3-5 times higher than that in the marine atmospheric zone. Therefore, when the effects of alloy elements on the corrosion resistance of low alloy steel are studied, the different corrosion environments must also be considered.

The respective corrosion rates of three sample steels from the 18 different steels: $\mathrm{A}_{3}$ steel, $10 \mathrm{Cr}_{2} \mathrm{AlMo}$ steel and $17 \mathrm{NiCuP}$ steel, are shown in figures 5-7.

Figures 5 and 6 show that in the splash zone, the corrosion rates of $10 \mathrm{Cr}_{2} \mathrm{AlMo}$ steel and $\mathrm{A}_{3}$ steel had no obvious diffe-

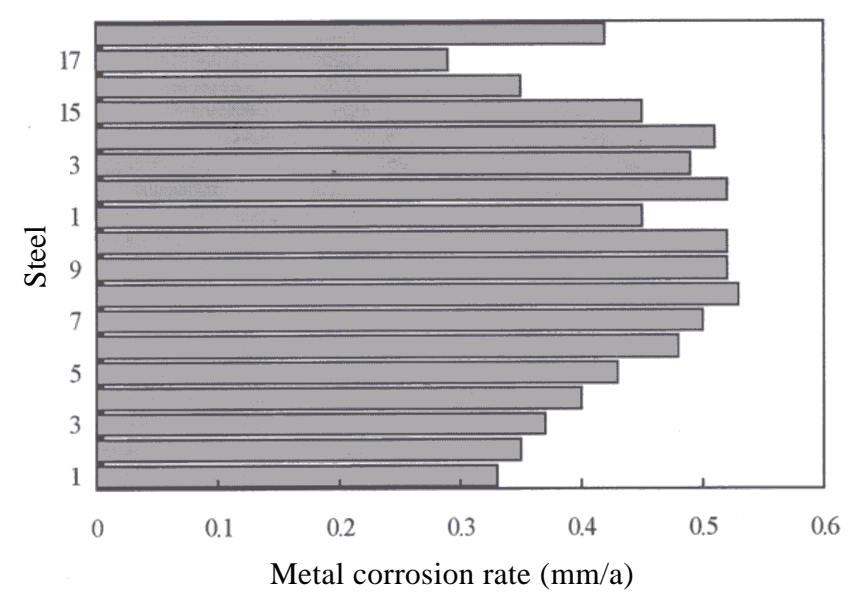

Figure 3. Corrosion rate of 18 types of steels in splash zone.

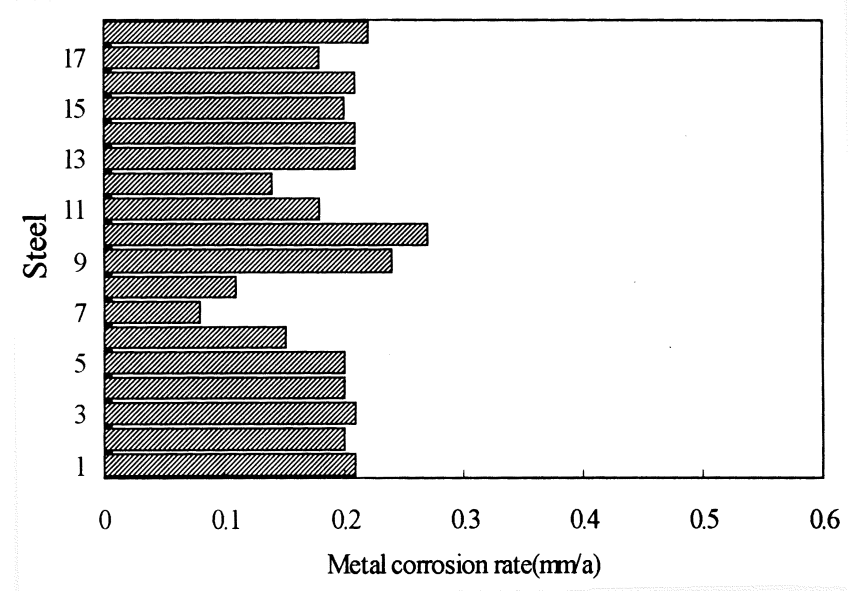

Figure 4. Corrosion rate of 18 types of steels in the immersion zone. rence, while in the seawater zone, the corrosion rate of $\mathrm{A}_{3}$ steel was three to four times that of the $10 \mathrm{Cr}_{2} \mathrm{AlMo}$ steel.

Figures 5 and 7 show that in the seawater zone, the corrosion rate of $17 \mathrm{NiCuP}$ steel (figure 7) was a little higher than that of the general carbon steel. In the splash zone, the corrosion of $\mathrm{NiCuP}$ steel was considerably lower than that of the general carbon steel (figure 5).

Figures 6 and 7 show that, in the seawater zone, the corrosion rates of $10 \mathrm{Cr}_{2} \mathrm{AlMo}$ steel were lower than those of the $17 \mathrm{NiCuP}$ steel (figure 7). While in the splash zone, things changed radically, and the corrosion rates of $10 \mathrm{Cr}_{2} \mathrm{AlMo}$ steel were higher than those of the $17 \mathrm{NiCuP}$ steel. (The reason has been discussed in another paper.)

The corrosion rates of the three steels in different environments show that different kinds and amounts of alloy elements added to carbon steel had distinctively different effects on the corrosion resistance of low alloy steel. The same alloy elements on the other hand, had different effects on the corrosion resistance of low alloy steel in different environments.

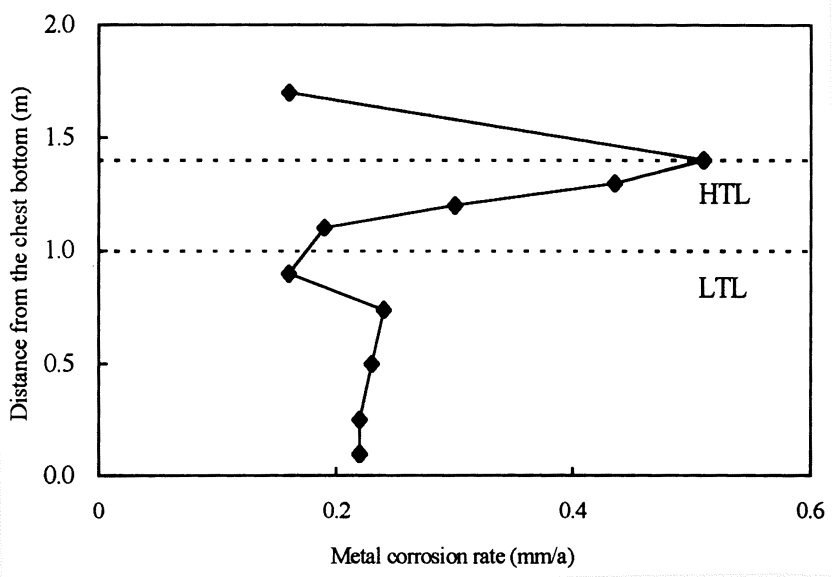

Figure 5. Corrosion rate of $A_{3}$ steel.

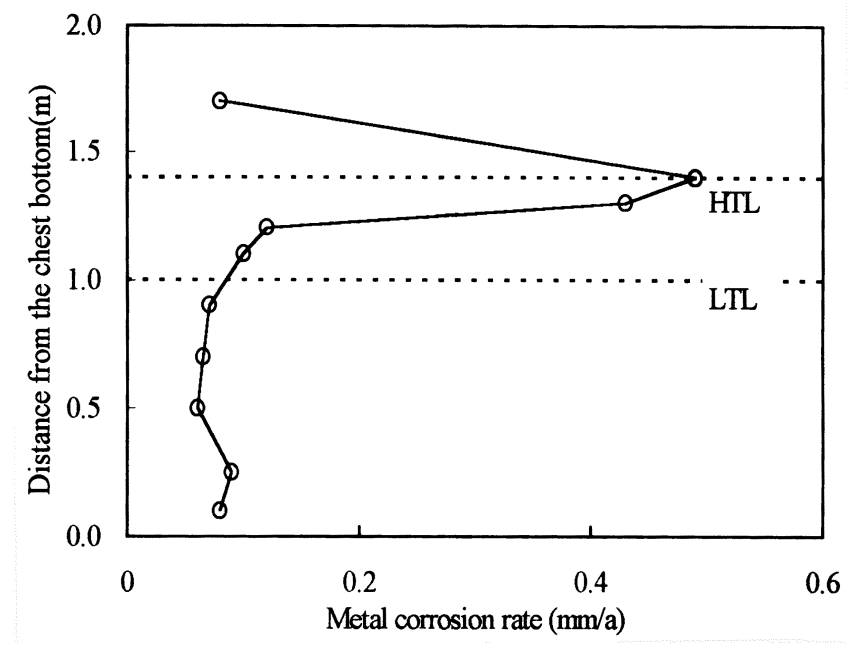

Figure 6. Corrosion rate of $10 \mathrm{Cr}_{2} \mathrm{AlMo}$ steel. 


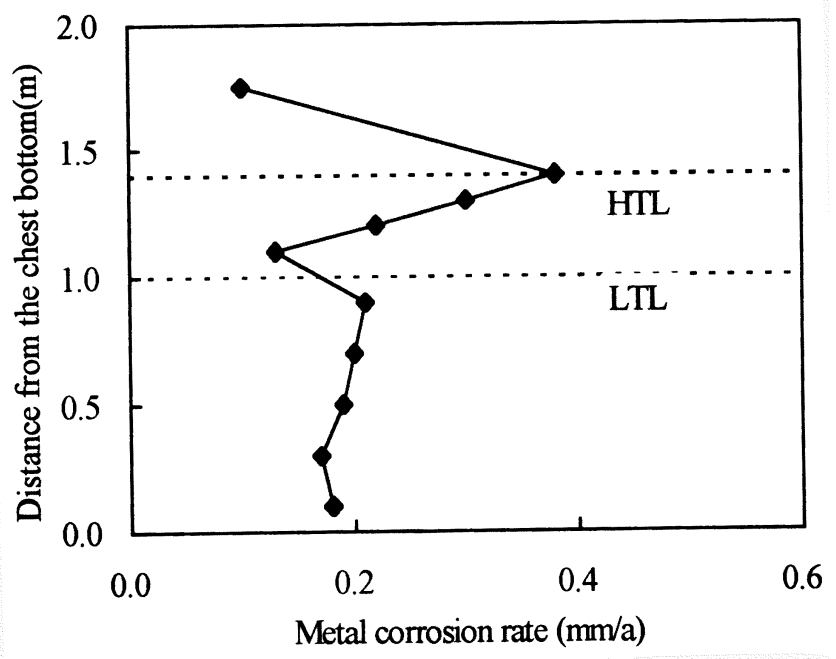

Figure 7. Corrosion rate of $17 \mathrm{NiCuP}$ steel.

The relationship of the corrosion rate of low alloy steel in marine environment and the composition of alloy elements in the steel is fairly close, and cannot be described by a simple mathematical formula. A vast amount of test data was used to derive the following regression equations through regression analysis using computer (Xia et al 1995).

The regression equation for low alloy steel corrosion in the marine atmospheric zone was found to be

$$
\begin{aligned}
Y= & 0 \cdot 2281-0 \cdot 059[\mathrm{Mn}]-0 \cdot 2193[\mathrm{P}]-0 \cdot 0336[\mathrm{Si}] \\
& +0 \cdot 00365[\mathrm{Cr}]-0 \cdot 1548[\mathrm{Mo}]-0 \cdot 0976[\mathrm{Al}] \\
& -0 \cdot 1787[\mathrm{Cu}]+0 \cdot 0567[\mathrm{~V}],
\end{aligned}
$$

where $Y$ is corrosion rate and $[\mathrm{Mn}],[\mathrm{P}],[\mathrm{Cr}],[\mathrm{Mo}],[\mathrm{Al}]$ stand for the amount of alloy elements used.

So, for steel in the marine atmospheric zone, the most effective alloy elements were $\mathrm{P}$ and $\mathrm{Cu}$, the second most effective was Mo, but V was harmful. Adding V probably decreased the corrosion resistance of steel, but its effect was not obvious because the regression coefficient was only 0.0567. The regression equation for splash zone was as follows:

$$
\begin{aligned}
Y= & 0 \cdot 5613-0 \cdot 0855[\mathrm{Mn}]-0 \cdot 5214[\mathrm{P}]+0 \cdot 0235[\mathrm{Si}] \\
& +0 \cdot 0751[\mathrm{Cr}]-0 \cdot 2665[\mathrm{Mo}]-0 \cdot 0185[\mathrm{Al}] \\
& -0 \cdot 2051[\mathrm{Cu}]+0 \cdot 0561[\mathrm{~V}] .
\end{aligned}
$$

For steel in the splash zone, the most effective alloy elements were $\mathrm{P}, \mathrm{Mo}$ and $\mathrm{Cu}$.

The regression equation in seawater zone was as follows:

$$
\begin{aligned}
& Y=0 \cdot 2297-0 \cdot 0087[\mathrm{Mn}]+0 \cdot 0047[\mathrm{P}]+0 \cdot 0494[\mathrm{Si}] \\
& +0 \cdot 002[\mathrm{Cu}]-0 \cdot 0267[\mathrm{Mo}]-0 \cdot 1437[\mathrm{Al}] \\
& -0 \cdot 1117[\mathrm{Cr}]+0 \cdot 0578[\mathrm{~V}] .
\end{aligned}
$$

For steel in the seawater zone, the most effective alloy elements were $\mathrm{Al}$ and $\mathrm{Cr}$.

\section{Conclusions}

(I) The regression equations for low alloy steel corrosion in marine atmospheric zone, splash zone and seawater zone were established through regression analysis of the alloy elements and the corrosion resistances of steels using computer. The correctness of the results was $83 \%$.

(II) Different alloy elements had different effects on the corrosion rate of steels in different marine environments. For example, the efficient anti-corrosion steels containing $\mathrm{Cr}$ and $\mathrm{Al}$ showed no evident corrosion resistance properties in the splash zone. So study of the effect of alloy elements on the corrosion resistance of low alloy steel must take into account the corrosive environments where they are used.

(III) The corrosion resistance of steel in the marine atmospheric zone was obviously increased by $\mathrm{Cu}, \mathrm{P}$ and $\mathrm{Mo}$; in the splash zone it was increased by $\mathrm{P}, \mathrm{Mo}$ and $\mathrm{Cu}$; in the seawater zone it was increased by $\mathrm{Al}$ and $\mathrm{Cr}$ in seawater zone.

(IV) Because of the limitations of the amount of different kinds of steels and testing time, the results of this test were not very satisfactory, so further research is still needed.

\section{References}

Hou Baorong 1981 Studia Marina Sinica 1887

Hou Baorong and Zhang Jinglei 1980 Marine Sci. 416

Xia Lenjin et al 1995 Studia Marina Sinica 36145 